\title{
Stimulating an Interest in Engineering Through an "Explore Engineering and Technology" Summer Camp for High School Students
}

\section{Dr. Anca L. Sala, Baker College, Flint}

Dr. Anca L. Sala is Professor and Dean of Engineering and Computer Technology at Baker College of Flint. In addition to her administrative role she continues to be involved with development of new engineering curriculum, improving teaching and assessment of student learning, assessment of program outcomes and objectives, and ABET accreditation. She is a founding member of Mi-Light Michigan Photonics Cluster, and is active in the ASEE, ASME, and OSA professional societies serving in various capacities.

\section{Dr. Pattabhi Sitaram, Baker College, Flint}

Dr. Sitaram is an Associate Professor and Chair of the Department of Engineering at Baker College in Flint, Michigan. He worked in the automotive industry, mainly at GM for fifteen years as a simulation and methods development engineer in crashworthiness. He hast taught extensively at both undergraduate and graduate levels in Civil and Mechanical Engineering disciplines. His research interests include Finite Element Analysis \& Design, Crashworthiness, and Plates \& Shells.

\section{Mr. Tom Spendlove, Baker College, Flint}

Tom Spendlove teaches Engineering, CAD, and machining courses at Baker College of Flint in Flint, Michigan. He shifted to education after ten years of product design in the automotive field. Areas of interest and study are $3 \mathrm{~d}$ printing, the design process, and engineering education. 


\title{
Stimulating an Interest in Engineering through an "Explore Engineering and Technology" Summer Camp for High School Students (Research to Practice) Strand: Other
}

\begin{abstract}
Attracting a larger number of young people to Science, Technology, Engineering and Mathematics (STEM) careers is critical to the United States being able to remain globally competitive. One increasingly popular approach by colleges and universities to this end is to offer on-campus STEM summer camps to high school and middle school students. Our College has offered one-week Robotics summer camps for high school and middle school students every summer since 2009. The Robotics camps fit naturally with the large number of FIRST Robotics teams in our area whose students welcome the opportunity to continue learning and practicing skills in the off-season. For the 2013 high school summer camp however, engineering faculty in the Division decided to broaden the scope of the camp to introduce a wider population of students to engineering and technology.
\end{abstract}

The "Explore Engineering and Technology" camp attracted a full group of 27 students in its first run, out of which eight were female. The one-week camp was structured around different engineering disciplines - civil, computer, electrical, mechanical, and optical engineering. A total of nine instructional modules, each three-and-a-half-hour long, were developed and taught by engineering faculty during the camp. Groups of students rotated through morning and afternoon sessions conducted in our engineering laboratories. They were given an introduction to fundamental engineering principles followed by hands-on experimentation in the lab. In addition to the faculty members teaching the program, a couple of undergraduate engineering students were present to help and mentor, which turned out to be a great learning experience for them. To conclude the camp, participants were asked to choose one of the modules from which to prepare and give an oral presentation during the last session. A competition for the top three presentations was set-up and awards were given.

The paper discusses the content of the modules and the results of the camp as evidenced by student presentations and student surveys. The camp was successful in increasing students' interest and confidence in pursuing careers in engineering and technology. Lessons were also learned from the first offering of the camp leading to plans for future improvement. These include development of a Workbook/Lab Manual summarizing all modules for students to use during the camp as well as keep for future reference. Future plans also include adding new activities and experiments to accommodate both new and returning students.

\section{Introduction}

STEM summer camps for high school and even middle school students offered on campus by colleges and universities have become extremely popular in the past decade. The Engineering Education Service Center (EESC), a company providing resources to K-12 educators to help promote STEM areas with a focus on Engineering, is compiling and publishing a directory of summer camps ${ }^{1}$, organized by state. Without being exhaustive, the directory includes hundreds of camps and offers a valuable glimpse into the variety of camps that are available. An important objective of summer camps is to stimulate and increase interest, as well as confidence, in pursuing a STEM or engineering career among young people, including under-represented 
minorities. This is a very important goal as STEM based occupations are expected to increase in the future ${ }^{2}$, while the enrollment in STEM programs in the United States continues to lag behind $^{3}$. Another objective of summer camps is to introduce students to the campus of the university or college offering the camp and to help with future student recruitment.

A good grouping of various summer camps is provided by Robert Fletcher in a paper presented at the ASEE Annual Conference and Exposition in 2010 ${ }^{4}$. According to Fletcher there are four types of summer camp programs: "1. introduction to engineering programs that expose the student to the broad and many aspects of engineering; 2 . topical programs that concentrate on a specific technical area or field; 3. programs that target specific segments of the population that may be under-represented in the engineering disciplines; and 4. summer camps that focus on teaching public school teachers about engineering". The summer camp described by Fletcher in his paper falls in the second category, focusing on introducing students to Alternative Energy. Many camps fall in this category, for example a Nanoscale Science and Engineering camp 5 , and numerous Robotics ${ }^{6,7}$ camps. There are also many camps in the first category ${ }^{8,9}$. The camp described in this paper falls in the first group and summer 2013 was the first year we offered such a camp.

Our College has offered a Robotics summer camp for high school students for four consecutive years between 2009 and 2012, as well as a Robotics summer camp for middle school students from 2010 to 2013. The high school Robotics camps had a number of objectives, including attracting more students to STEM careers and introducing them to our campus. A very specific objective was to support the FIRST ${ }^{10}$ Robotics teams in our local area with activities throughout the off-season. Due to this latter objective the camp content focused on topics students learn when they participate in the FIRST Robotics competition, structured around designing, building, programming and testing an autonomous and teleoperated driving robot equipped with sensors. The Robotics camps were very successful and, as expected, attracted many student members or potential members of FIRST teams in our area.

In 2013 faculty in the Division of Engineering and Technology discussed expanding the summer high school camp to cover broader engineering topics, and also to attract a wider population of students than the FIRST Robotics participants. As the College is located in a county with some economically depressed areas, the desire was also to attract students from disadvantaged backgrounds and introduce them to engineering. To reflect the new camp content the name was chosen as "Explore Engineering and Technology Camp". The paper describes the organization of the new camp, its curriculum, the evaluation results, the lessons learned, and the plans for future improvements.

\section{"Explore Engineering and Technology" Summer Camp}

The "Explore Engineering and Technology" summer camp for high school students was offered for the first time during the week of July 8 - 12, 2013 at Baker College, Flint Campus. The camp was capped to 27 participants and it reached the maximum capacity well before its July 8 start. The camp was organized as a commuter camp, with participants being responsible for their own transportation to and from the College. There was no cost for the participants. This included lunch paid for by the College. The camp was offered at no cost to broaden the participation of students and include students from disadvantaged backgrounds. 
The camp was advertised through flyers sent to all school districts in the area, which included an application form to be filled and returned by interested participants. Eligible students were those entering $9^{\text {th }}$ to $12^{\text {th }}$ grades in fall 2013. The application asked students to describe their interests and abilities in STEM fields in a short paragraph. GPA was not used as a criterion to select students. A committee of faculty members reviewed the applications and selected the camp participants. The committee based its selection on applicants' description of their STEM interests and previous experiences. As this was the first time the camp was offered, we used rolling admission to fill the camp. Once the maximum capacity was reached, we placed the next couple of qualified applicants on a wait list in case some of the ones already admitted would later decide not to attend. Out of the 27 participants there were eight females. Eleven schools were represented and the majority of the participants, 14 out of 27 , were entering $10^{\text {th }}$ grade. Among the schools represented several were located in economically depressed parts of the county.

\section{a) Schedule}

The camp schedule was Monday - Friday, from 8:30am to 4:00pm, with one half hour for lunch between 12:00-12:30pm. The total number of hours of instruction was 35. Participants attended two sessions every day, each session 3.5 hours long, one in the morning and one in the afternoon, for a total of nine sessions. The afternoon session on the last day of camp was dedicated to student presentations competition and the award ceremony.

At the beginning of the camp students were divided in three groups of nine, which we labeled A, $\mathrm{B}$ and $\mathrm{C}$ to help with the logistics of rotating students through the instructional modules. The nine instructional modules were labeled $1-9$. The table below was given to students to help orient them vs. the order of the sessions. Details about each session are provided in the next section.

Table 1. Schedule of sessions 1-9 for each of the three student groups labeled A, B, and C.

\begin{tabular}{|l|c|c|c|c|c|c|}
\hline & Faculty 1 & Faculty 2 & Faculty 3 & Faculty 1 & Faculty 2 & Faculty 3 \\
\hline Monday & A1 & B7 & C4 & C1 & A7 & B4 \\
\hline Tuesday & B1 & C7 & A4 & A2 & B8 & C5 \\
\hline Wednesday & C2 & A8 & B5 & B2 & C8 & A5 \\
\hline Thursday & A3 & B9 & C6 & C3 & A9 & B6 \\
\hline Friday & B3 & C9 & A6 & \multicolumn{2}{|c|}{ Final Presentations } \\
\hline
\end{tabular}

Three faculty members co-taught the camp, each being responsible for three modules. Faculty received help from two undergraduate mechanical engineering students and a lab technician every day of the camp. In addition, two adjunct faculty members participated in some of the sessions. Involving the undergraduate students proved very beneficial for the students themselves, the high school students, and the faculty. The undergraduates discovered they enjoyed teaching and mentoring younger students. One of them had never interacted with young people in this way before the camp. Both mechanical engineering students described their positive experiences with the camp to faculty in oral communications. They expressed interest in returning for future camps as well as considering teaching engineering as a possible career path. 
At the same time the high school students appreciated the more informal interaction they had with the undergraduates and felt more at ease asking them questions.

Based on this positive experience faculty is planning to involve undergraduate students even more in the next offering of the camp, which will require more extensive preparation before the start of the camp. Next summer the undergraduate students will be given the responsibility of teaching some portions of the modules in addition to helping with the experiments in the lab, which was their primary responsibility this time.

b) Curriculum

The nine instructional modules taught during the "Explore Engineering and Technology" camp were the following:

1. Materials Science

2. Engineering Computation: Excel and Matlab

3. Mechanics of Materials

4. Computer Aided Engineering

5. Advanced Manufacturing

6. Thermal Science

7. Photonics and Lasers

8. Electrical Engineering

9. Computer Engineering

Modules 1-3 were taught by one faculty member, 4-6 by another, and 7-9 by a third faculty member. All modules were taught in a laboratory setting, and consisted in a short lecture followed by experiments performed by the students. The lecture of about half an hour introduced students to the fundamental principles in each area and to some of their main applications. A presentation of the lab equipment followed together with safety instructions. Students were then given experiments to perform under supervision from faculty and assistants. Modules 2 and 4 took place in a computer lab. The following table presents details on the topics and lab experiments performed by the students.

Table 2. Topics presented in each of the nine modules.

\begin{tabular}{|l|l|}
\hline Module & Topics and lab experiments \\
\hline Materials Science & $\begin{array}{l}\text { Sample preparation for microstructural analysis, microstructural analysis } \\
\text { using a microscope, Rockwell hardness testing }\end{array}$ \\
\hline $\begin{array}{l}\text { Engineering Computation: } \\
\text { Excel and Matlab }\end{array}$ & $\begin{array}{l}\text { Using Excel and Matlab to solve linear simultaneous equations, single } \\
\text { nonlinear equation, matrices, eigenvalue problems. Graphing. }\end{array}$ \\
\hline Mechanics of Materials & $\begin{array}{l}\text { Tensile test of steel and aluminum specimens, Charpy impact test, } \\
\text { deflection of beams }\end{array}$ \\
\hline $\begin{array}{l}\text { Computer Aided } \\
\text { Engineering }\end{array}$ & $\begin{array}{l}\text { Basic rules of sketching, drafting and projection. Creating 3-D objects } \\
\text { using ProEngineer software. }\end{array}$ \\
\hline Advanced Manufacturing & $\begin{array}{l}\text { Precision measurements, area, volume and weight calculations, making } \\
\text { simple objects using 3D printers }\end{array}$ \\
\hline Thermal Science & Thermodynamics experiments, hydrostatic pressure \\
\hline Photonics and Lasers & Basic properties of light, measuring the speed of light, fluorescence \\
\hline
\end{tabular}




\begin{tabular}{|l|l|}
\hline Electrical Engineering & $\begin{array}{l}\text { Assembling simple electric circuits using a breadboard, measuring } \\
\text { voltage, current, resistance and power }\end{array}$ \\
\hline Computer Engineering & $\begin{array}{l}\text { Explore 8-bit microprocessor development boards (PIC18), instruction } \\
\text { set architecture, embedded system applications }\end{array}$ \\
\hline
\end{tabular}

Figure 1 shows students working on experiments in the Materials Science Lab, and the Optics and Photonics Lab.
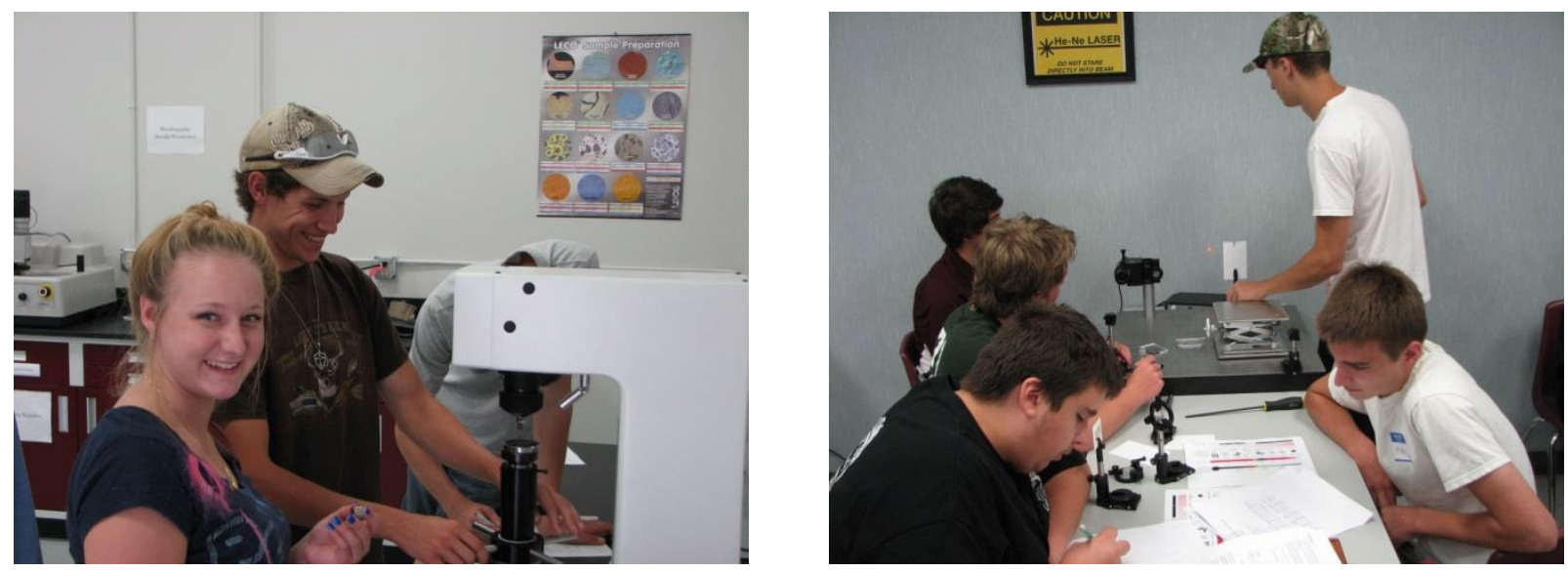

Fig.1 a) Students performing Rockwell hardness testing in the Materials Science Lab; b) Students working in the Optics and Photonics Lab

\section{c) Student Presentations}

Students learned at the beginning of the camp that they will have to prepare an oral presentation from a module of their choice, and give this presentation during the last day to an audience that will include everyone involved with the camp. The Dean of Engineering was invited to the final presentations as well as any interested parents. Students formed their own groups to work on the presentations, with the recommendation not to have more than three students in one group. The presentations were judged by a committee made out of the faculty members teaching the camp and the Dean, and the top three presentations were awarded prizes. All students in the camp received certificates of achievement and T-shirts, handed by the Dean after the presentation competition.

The most popular module chosen by students to base their presentation on was "Advanced Manufacturing" with three presentations. This was followed by "Materials Science" and "Computer Aided Engineering" with two presentations each, and "Engineering Computation" and "Electrical Engineering" with one presentation each. The remaining four modules, on "Mechanics of Materials", "Thermal Science", "Photonics and Lasers" and "Computer Engineering" were not chosen by any group for the final presentation. Faculty has discussed these latter modules and will look into possible improvements to make them more attractive to students. Collecting more data from the next group of students will also help to better understand students' perceptions of these topics.

The final presentations were creative and had good content, but were presented in a somewhat informal manner. For example, students included only their first name on the first slide. Faculty 
provided recommendations for improvement in both content of the slides as well as in their delivery. The top three presentations were as follows: first place presentation was on "Materials Science", second place presentation was on "Engineering Computation", and third place presentation was on "Computer Aided Engineering". Four of the eight girls participating in the camp were part of the teams that took first and second place in the presentation competition.

\section{d) Assessment Results and Discussion}

Two surveys were given to camp participants to judge the impact of the camp activities on their interest and confidence in pursuing an engineering career. A short pre-camp survey administered the first day of the camp asked students about their general interest in enrolling in college and pursuing an engineering degree. The post-camp survey given in the last day was more extensive and asked questions about the camp impact on students' interest in engineering, their teamwork and presentation skills, the modules taught, the camp schedule, and suggestions for improvement. The possible answers to both survey questions were Strongly Agree, Agree, Neutral, Disagree, and Strongly Disagree.

The pre-camp survey questions were as follows:

1) I plan to go to college when I finish high school.

2) I am interested in a specific college(s).

3) I have a specific career goal(s).

4) I am interested in a career in engineering/4-year program.

5) I am interested in a career in technology/2-year program.

The figure below shows students responses to the pre-camp survey. The responses illustrate that this was a very focused group of students, with a large majority planning to enroll in college (96\%) and having very clear goals in mind (86\%). A large percentage of the students, $71 \%$, expressed their interest in engineering either at agree or strongly agree level.

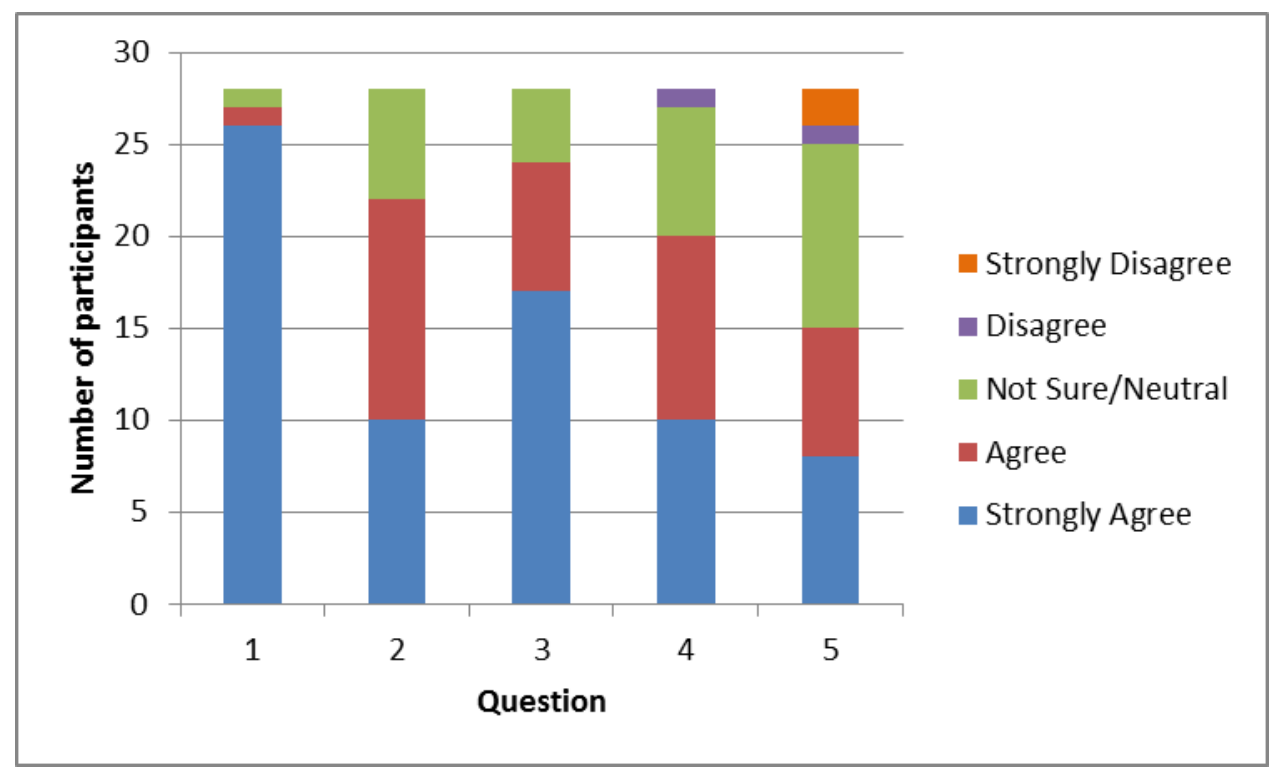

Fig.2 Student responses to pre-camp survey questions 
The post-camp survey questions were as follows:

1) The summer camp stimulated my interest in engineering.

2) The summer camp enhanced my interest in engineering.

3) The camp taught me teamwork and be a team player.

4) The camp helped me in improving my presentation skills.

5) Did you think that the number of activities was appropriate?

6) Did you think that the amount of material covered was appropriate?

7) I feel more confident now in pursuing a career in engineering.

Figure 3 shows the students responses to the post-camp survey. Only 25 students were present at the time when the post-camp survey was administered, and one student did not answer questions 5 and 6 . The responses show that $60 \%$ of students felt the camp stimulated and enhanced their interest in engineering (questions 1 and 2). A slight majority, 56\%, felt more confident about pursuing a career in engineering at the end of the camp (question 7). These percentages do not seem very high, but we have to keep in mind that 20 students already expressed an interest in engineering at the beginning of the camp.

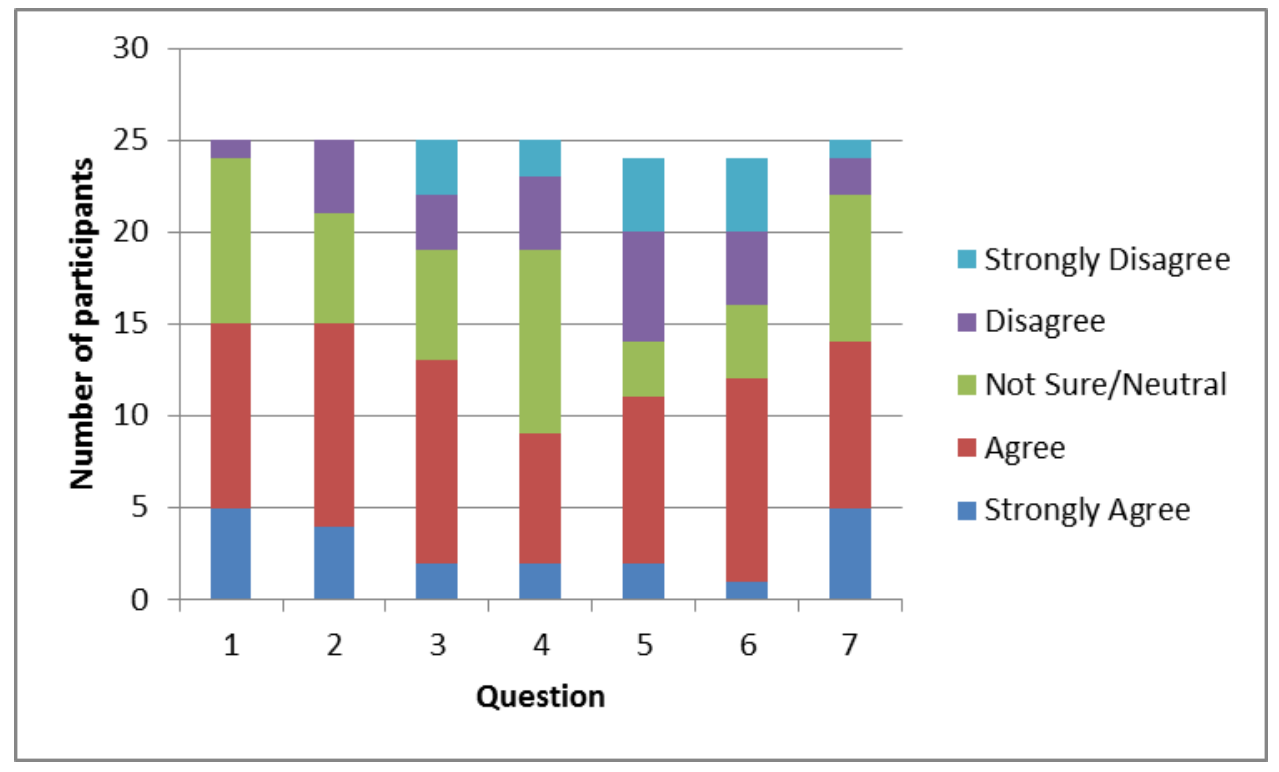

Fig.3 Student responses to post-camp survey questions

Responses to questions 3 and 4 about teamwork and presentation skills showed students did not feel they benefitted from the camp activities in these respects. The camp did not provide any instruction on how to create a good presentation, and students were on their own when putting their presentation together. Students' responses show this is an area in need of improvement for the next camp offering. Teamwork will also need to be pinpointed in discussions with students throughout the camp as being an essential part of engineering work. Some students attending the camp were members of FIRST Robotics teams. They brought with them the very competitive spirit of robotics events especially towards students from rival schools. In future offerings of the Explore Engineering and Technology camp we will include a segment about the importance of teamwork and the role played by different members of an engineering team. 
Questions 5 and 6 were about the activities and material covered during the camp. Responses here varied, with "agree" being mentioned the most. At the end of the survey we included an open ended question asking for students' comments and suggestions for improvements. About half of the students commented on having too much down time in some of the modules. They suggested adding activities such that the time is used more fully. This came as a surprise for us as we thought that we included a lot of material and activities, and students would be overwhelmed by all the information. That did not turn out to be the case for a good half of the participants. In future offerings we will add activities in the existing modules, and offer student groups the chance to go at their own pace. One of the additions will be a combination of Computer Aided Design and 3D printing activities, so that students will complete a cycle of designing and making the objects designed using the rapid prototyping machines. Overall the groups who are capable of doing more work will receive more challenges.

In comments students appreciated the hands-on aspects of the camp and asked for more hands-on experiences. Another suggestion was to allow groups to choose activities based on their preferences. This will be discussed among faculty, but the broad format of getting students to experience fundamental principles as well as different engineering disciplines will most likely remain.

Another portion of the post-camp survey asked students to rank the nine modules in their order of preference starting with the one they enjoyed the most. The module picked by most students as their favorite, with 14 votes out of 25, was the "Advanced Manufacturing" module where students had the opportunity to use several 3D printing machines to make their own objects. "Computer Aided Engineering" came in second, after which there was a wide distribution of votes among the other modules. The responses to this question were fairly consistent with the choice of module for the final presentation.

\section{Conclusions and Future Plans}

The first offering of the "Explore Engineering and Technology" summer camp at Baker College in July 2013 brought in a full group of 27 students and successfully introduced them to engineering principles and different engineering disciplines. Many of the camp participants were highly interested and motivated and provided us with very good feedback on the camp content and organization. Combining student feedback with faculty's own observations while teaching the camp will help us revise some aspects and make improvements for the offering of the same camp next summer.

One of the observations made by faculty members teaching the camp regarded the lack of a Lab Manual to summarize all experiments students participated in. Faculty members prepared slides used in their short lectures, planned their experiments, and some had worksheets for students to practice on. Students however were not provided with written material on the lab experiments. We plan to create such a Lab Manual for the next offering of the camp where all experiments will be gathered, and which will stay with the students after the camp ends.

As mentioned before, we plan to deepen and add activities in the existing modules so that different student groups will be challenged at different levels. This will also help to diversify the activities such that students who attended previously will find new things to do if they return to 
the camp. A better selection of students will allow us to hopefully have students who are all motivated to learn throughout the camp. Even though the vast majority of students at the 2013 camp fit this profile, we did have a few who were less interested and they sometimes disrupted the work of the group they were part of. With all these plans for additions and improvements we are looking forward to the next "Explore Engineering and Technology" summer camp in 2014.

Finally, the pre- and post-camp survey questions will be revised to provide a more nuanced picture of the camp impact on participants' interest and confidence in pursuing engineering careers.

\section{References}

1. Engineering Education Service Center, Pre-Engineering Summer Camps http://www.engineeringedu.com/store/index.php?route=information/information\&information_id=8, accessed on Jan. 2, 2014

2. "Employment Outlook for STEM Professionals Is Robust - and Moving Beyond Traditional Occupations" Thomasnet Career Journal, Jan. 3, 2014 http://www.thomasnet.com/journals/career/employment-outlook-for-stem-professionals-is-robust-and-movingbeyond-traditional-occupations

3. "STEM in Postsecondary Education: Entrance, Attrition, and Course Taking Among 2003-04 Beginning Postsecondary Students", US Department of Education, Oct. 2012 http://nces.ed.gov/pubs2013/2013152.pdf

4. R. Fletcher, "Using an Alternative Energy Summer Camp for High School Students as a University Outreach Program for the Recruitment of Future Engineering Students: A Two Year Study", 2010 ASEE Annual Conference and Exposition, paper AC2010-1219

5. N. Healy, A. Berenstein, "Using Summer Programs to Excite Secondary Students about Nanoscale Science and Engineering”, 2013 ASEE Annual Conference and Exposition, paper AC2013-6269

6. M. Ayar, B. Yalvac, F. Ugurdag, A.Sahin, “A Robotics Summer Camp for High School Students: Pipelines Activities Promoting Careers in Engineering Fields", 2013 ASEE Annual Conference and Exposition, paper AC2013-6048

7. R. Stansbury, F. Behi, "Inspiring Interest in STEM through Summer Robotics Camp", 2012 ASEE Annual Conference and Exposition, paper AC2012-4304

8. M. Yilmaz, J. Ren, S. Custer, J. Coleman, "Hands-On Summer Camp to Attract K-12 Students to Engineering Fields", IEEE Trans. Education, Special Outreach Issue, vol. 53, 1, February 2010, pp. 144-151

9. M. Yilmaz, J. Ren, D. Ramirez, S. Custer, J. Coleman, “An Improved K-12 Outreach Camp for Engineering Disciplines", 2010 ASEE Annual Conference and Exposition, paper AC2010-1418

10. FIRST, For Inspiration and Recognition of Science and Technology, www.usfirst.org, accessed Jan. 2, 2014 